درجة إصابة الطفل الريفي ( عمر سنة - سنتين ) بالأنيميا الغذائية وعلاقتها ببعض المتغيرات ببعض قرى مركز كفر الدوار بمحافظة البحيرة

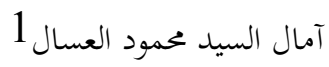

متغيرات الدراسة

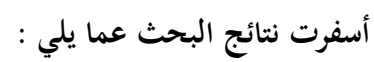

- 92 \% من الأطفال المبحوثين مصابين بالأنيميا ( 57 \% منهم بائين

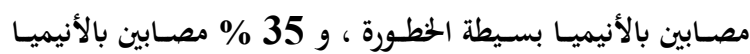

$$
\text { متوسطة الخطورة ( }
$$

- 40 \% من الأطفال أوزافـم في المدى الطبيعي المناسب لأعمارهم

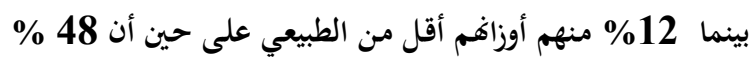

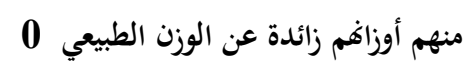

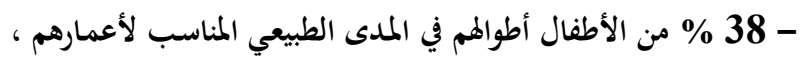

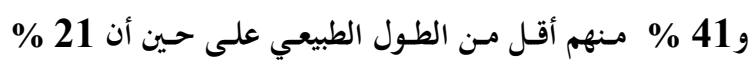

$$
\text { أطوالمم تزيد عن الطول الطبيعي }
$$

- 23 \% من الأطفال لم يتناولوا مجموعة اللحوم وبدائلها بأي كمية في

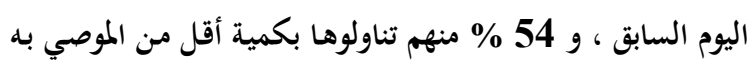

على حين أن 23 \% منهم تناولوها بالكمية الموصي بها 0 \%

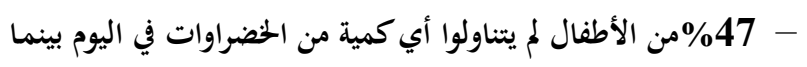

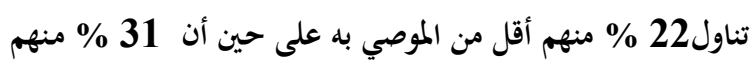

$$
\text { تناولوها بكميات في المدى الموصي }
$$

- 23 \% من الأطفال لم يتناولوا أي كمية من مجموعة الفاكهة بينما

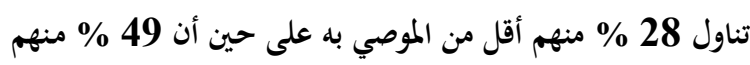

$$
\text { تناولوها في المدى الموصي به } 0
$$

- 28 \% مـن الأطفـال لم يتنـاولوا أي كميـة مـن مجموعـة الألبـان

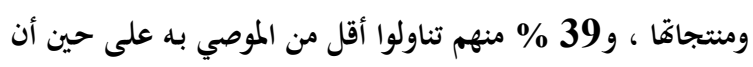

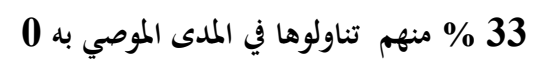

- 31 \% من الأطفال تناولواكميات من جمموعة الحبوب ومنتجاتما

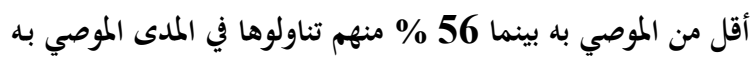
في اليوم على حين أن 13 \% منهم تناولوا أكثر من الموصي به.

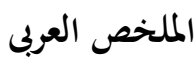

أجريت الدراسة للأهداف التالية :
2 - تقييم الحالة التغذوية للأطفال المبحوثين من حيث الوزن والطول

الحلالي لهم ومقارنته بالمدى الطبيعي وفقاً لأعمارهم 3 - التعرف على نمط الاستهلاك الغذائي للأطفال المبحوثين ومقارنته باحتياجاتم الموصي بها لأعمارهم 0 4 - قياس مستوى معسارف وممارسـات أمهات الأطفال فيمـا يتعلق بتغذية أطفالن 0

5 - التعرف على بعض الخصائص الشخصية والأسرية المميزة للأطفال المبحوثين.

6 - تحديد العلاقة بين درجة إصابة الأطفال المبحوثين بالأنيميا الغذائية وبعض المتغيرات موضع الدراسة المثتملة على الوزن والطول الحالي

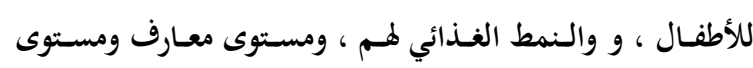

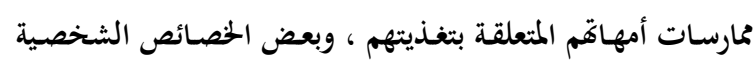
والأسرية المميزة لهم 0 أجريت الدراسة في مركز كفر الدوار بمحافظة البحيرة ومنه تم اختيار أكثر مراكز رعاية الأمومة والطفولة في عدد الأطفال المترددين للتطعيم الديم

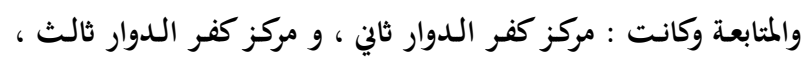

$$
\text { مركز الرعاية بمستشفى سيدي غازي } 0
$$

ممعت البيانات بالمقابلة الشخصية باستخدام استمارة استبيان من عينة

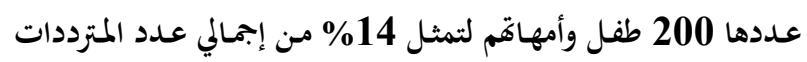
على مراكز رعاية الأمومة والطفولة المختارة خلال شهرين

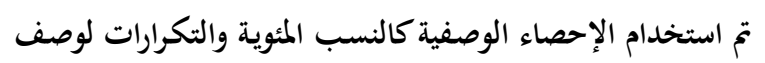

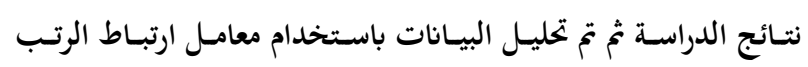

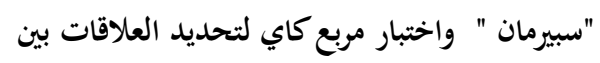

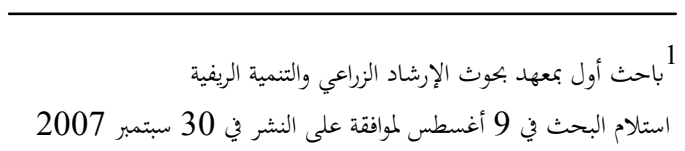


كالبروتين، والحديد وممض الفوليك ، وفيتامين ب12، وعنصرا

$$
0 \text { النحاس والكوبلت ( } 2005 \text { Coyer }
$$

وتعتبر الأنيميا الغذائية مـن أهم المشاكل الغذائية واسعة الانتشار

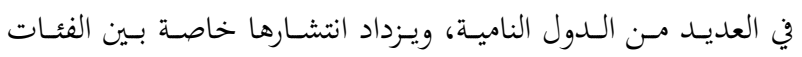
الحساسة ( كالحوامل والمرضعات والأطفال والمراهقات والشيوخ). وأشارت who who (1996) إلي وجود مشكلة انتشار عالي للأنيميا

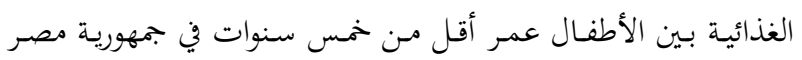
العربية حيث أن أكثر من40 \% من الأطفال في ذلك العمر تنخفض من فئ

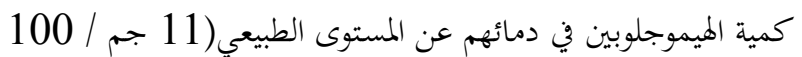
سم3 دم )، وأظهـرت نتـائج المسـح الشـامل الـذي تم إجـراؤه بجمهوريـة مصر العربية لتقييم الحالة التغذوية للأطفال إصابة $48.5 \%$

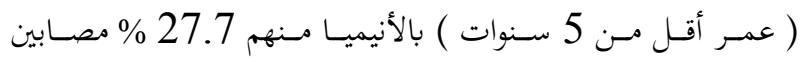

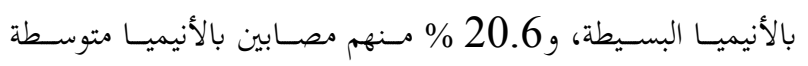
الخطورة بينما 0.3 \% فقط لـديهم إصابة بالأنيميا شـديدة الخطورة

0 ( 2005 DHS) وبينت دراسة Ghoneim \& Ahmed ( 2000 ) التي أجريت في بعض أحيـاء مدينـة الإسكندرية إصـابة 48.6 \% مـن الأطفـال

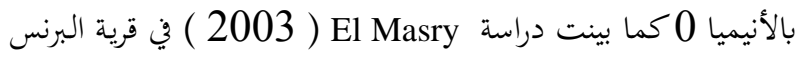
شـرق مدينـة الإسـكندرية إصـابة 46.7 \% مـن الأطفـال الـريفيين بالأنيميا منهم 34 \% إصابتهم بالأنيميا بسيطة الخطورة، و 12.7

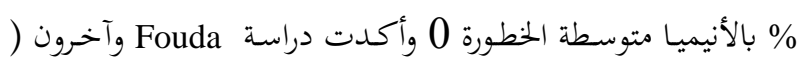
2004 ) إصابة 25 \% من الأطفال بقرية طاروت بالزقازيق بالأنيميا

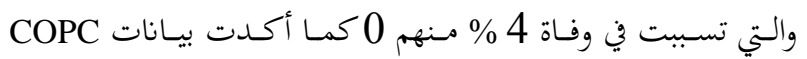
(2005 ) إصـابة 46 \% مــن الأطفــال بقريـة النحــاس بالزقـازيق 0 وأظهـر Wachs وآخـرون في دراسته (2005 ) ارتبـاط درجـة إصابة الطفل بالأنيميا الغذائية بعدة عوامل واخرول دراسل 1- عوامـل بيئية كندرة الغذاء الذي يجـب تناوله وعـدم توفره بالبيئة المحيطة، وكذلك مدى تلوث البيئة المحيطة

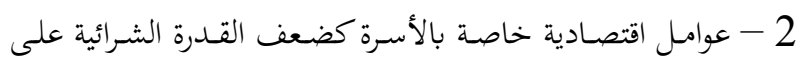
شراء الغذاء المتاح0
- 53 \% مـن أمهـات الأطفـال مسـتوى معـارفهن مـنخفض بالتغذيـة

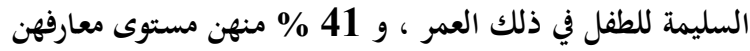
متوسط على حين أن 6 \% فقط مستوى معارفهن مرتفع 0 - 60 \% مـ أمهـات الأطفـال مسـتوى ممارستـهن للتغذيـة السـليمة لأطفالهن منخفض، 37 \% منهن مستوى ممارستهن متوسط على مئى حين أن 3 \% فتط مستوى ممارستهن مرتفع 0 - بالتحليل الإحصائي للبيانات وجدت علاقة ارتباطية عكسية معنوية عند مسـتوى معنويـة 0.01 بين درجـة إصـابة الأطفـال المبحـوثين بالأنيميا وبين المتغيرات التالية : وزن الطفل، والكمية التي يتناولها

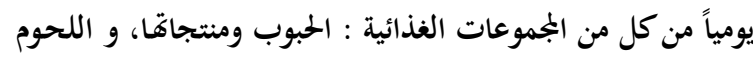

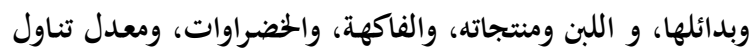

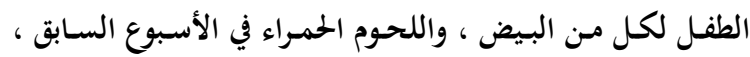

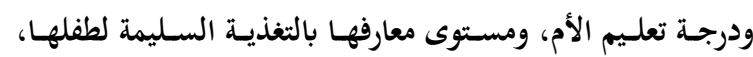
ومستوى ممارستها للتغذية السليمة لطفلها - كما وجـدت علاقة ارتباطية طردية معنوية عند مستوى معنوية 0.05 بين درجة إصابة

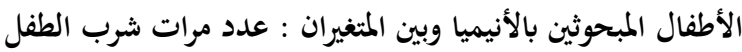

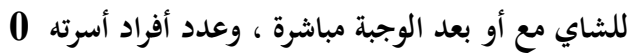

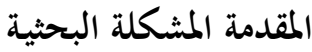

تعرف الأنيميا بصفة عامة بأها نقص في عدد خلايا الدم الحمراء

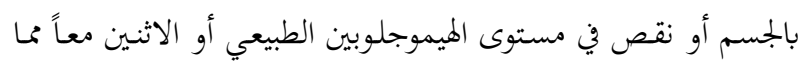

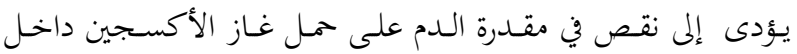
أنسجة الجسم 0 وتقسم الأنيميا وفقاً لأسباهما إلى: 1- أنيميا ما بعد النزيف : وتحدث نتيجة لزيادة فقد خلايا الدم

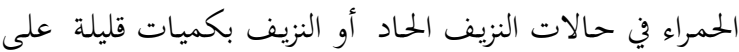

$$
\text { فترات طويلة ( كما في حالات البلهارسيا أو البواسير) } 0
$$

2 - أنيميا نتيجة لزيادة معدل تكسير خلايا الدم الحمراء وتحدث في

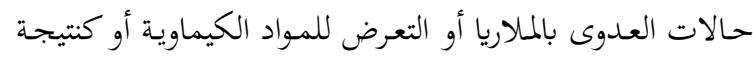

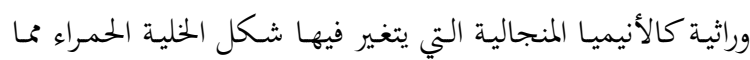

$$
0
$$

3 - الأنيميا الغذائية : وتحدث نتيجة لسوء التغذية بنقص عنصر أو

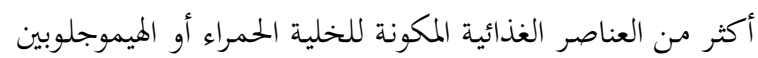


5 - الحسد من إصـابة الطفـل بالطفيليـات التي تسبب فقـد في كمية

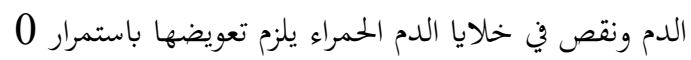

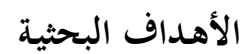

1- تحديد درجة إصابة الأطفال المبحوثين بالأنيميا الغذائية0

2- تقييم الحالة التغذوية للأطفال المبحوثين مـن حيث الوزن والطول

الحالي لمم ومقارنته بالمدى الطبيعي وفقاً لأعمارهم 0

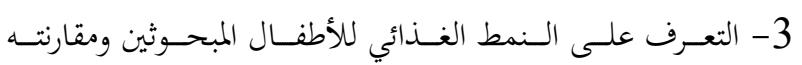

باحتياجاهم الموصي بها لأعمارهم 0

4- قياس مستوى معارف ومستوى ممارسات أمهات الأطفال فيما

يتعلق بتغذية أطفالهن في ذلك العمر 0

5- التعرف على بعض الخصائص الشخصية والأسرية المميزة للأطفال

المبحوثين

6- تحديـد العلاقـة بـين درجــة إصـابة الأطفـال المبحـوثين بالأنيميـا

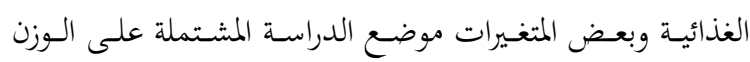

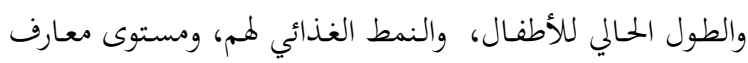

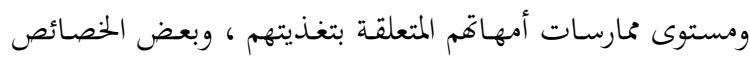

\section{الشخصية والأسرية المميزة لهم 0

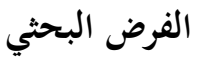

تم صياغة الفرض البحثي ليحقق الهـدف السـادس للدراسة كمـا يلي:

توجـد علاقة بين درجة إصـابة الأطفال المبحوثين بالأنيميا الغذائية

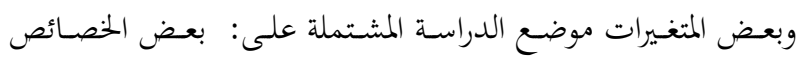

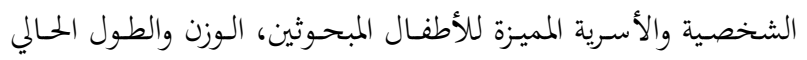
للأطفال، والنمط الغذائي لهم، ومستوى معارف ومستوى ممارسات أمهاتم المتعلقة بتغذيتهم 0

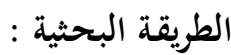

أولاً : منطقة البحث و العينة :

1- منطقة البحث: تم اختيار مركز كفر الدوار بمحافظة البحيرة ومنه تم اختيار أكثر مراكز رعاية الأمومة والطفولة في عدد الأمهات

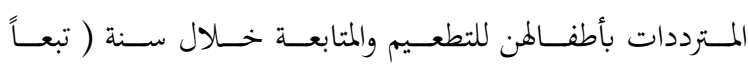

3 - عوامل اجتماعية خاصة بالوالدين وخاصة الأم كالتعليم ومستوى

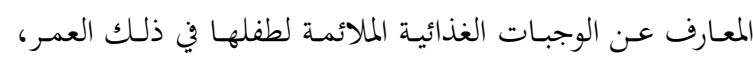
ومدى الاهتمام بنظافة الطفل الشخصية والغذائية0 وقد أشارت نفس الدراسة إلى وجود علاقة موجبة معنوية بين درجة تعليم الأم

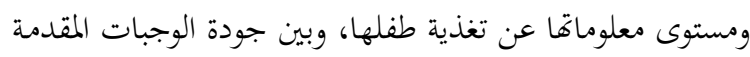
للطفل، وكذلك بين مستوى الميموجلوبين للطفل 0 وأظهـرت دراسـة Zlotkin ( 2003 ) أن إصـابة الأطفــال

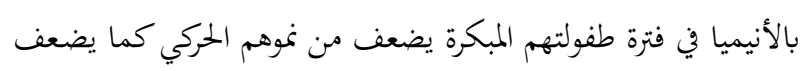

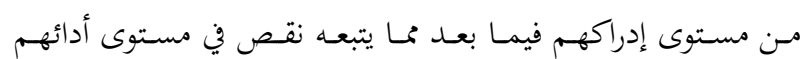
وإنجازهم الدراسي من مئواس إدراس وذكر 1996 Verster أن انتشار الأنيميا بين الأطفال في دولة

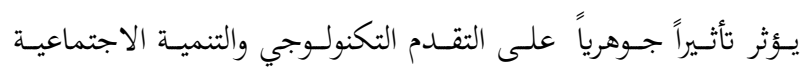
والاقتصادية ويؤدي إلانخفاض الدخل القومي لتلك الدولة لما للأنيميا

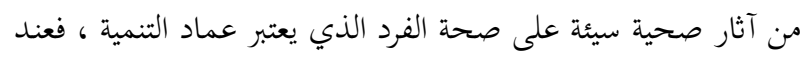
إصابة الطفل بالأنيميا يؤدي ذلك إلى الخفاض نقل صنل الدم إلى إلى أنسجة الجسم مما يتبعه هزال وتعب سريع ونقص في النشاط ( كسل دائم ) كما يحدث الخفاض في أداء نظام مناعة الجسم مما يجعله دائماً أكثر عرضـة للإصـابة بالأمسراض ، وأضـاف انسه لتجنـب إصـابة الأطفـال

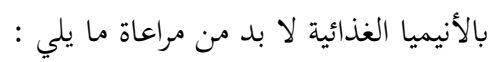
1

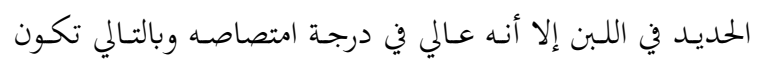

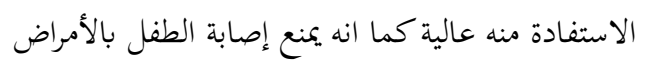
2 +إدخال الأغذية التكميلية و الأستبدالية للطفل في الوقت المحدد 3 - تناول الأغذية الغنية في محتواها من الحديد والبروتين خاصة من المصادر الحيوانية عالية الجمودة كاللحوم الحمراء والطيور والأسماك

$$
0 \text { والبيض }
$$

4- تحسـين القـدرة على امتصـاص الحديـد فعنـــ تنـاول الأغذيـة مـن

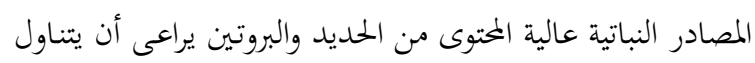

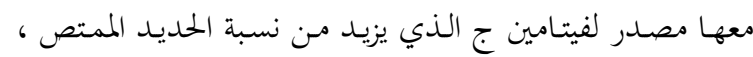
وبتحب تناول ما يعوق امتصاص الحديد كشرب الشاي مع الوجبة

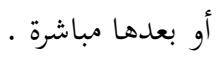


2 - التعرف على النمط الغذائي للطفل مـ حيث عـدد الوجبـات المتناولة في اليوم ، وعدد الرضعات ، وما تناوله من الأغذية طوال

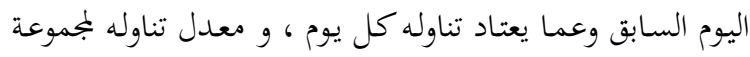

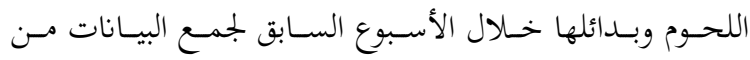

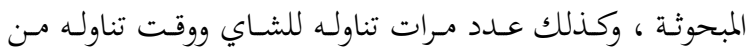

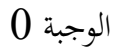

3 - التعرف على وعي الأمهات وممارستهم لأهم البنود المتعلقـة

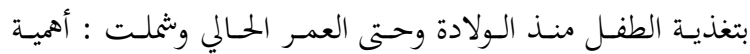

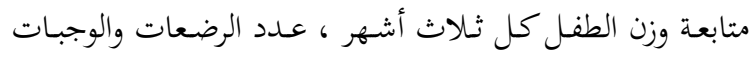

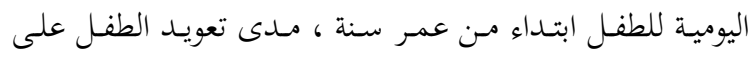

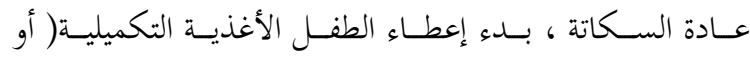

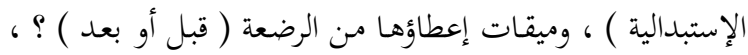
نوع الأغذية التي تعطى للطفل في كل شهر من عمره ؟ والصورة

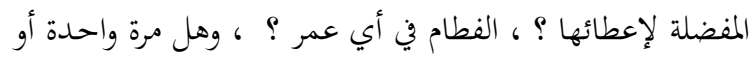
تدريجياً ؟

ثالثاً : قياس متغيرات الدراسة : 1 - المتغسير التـابع : درجــة إصـابة الأطفــال المبحــوثين بالأنيميـا

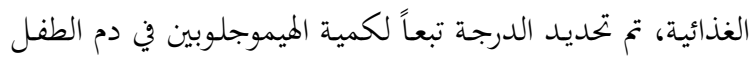

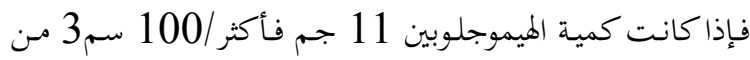

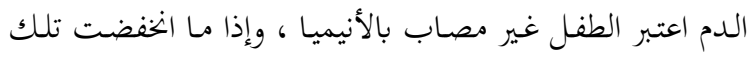

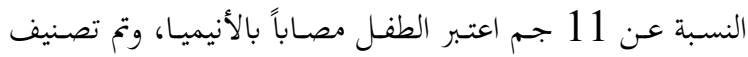

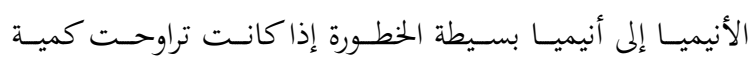

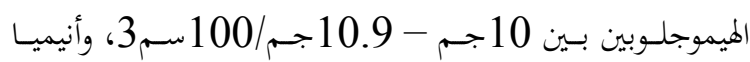

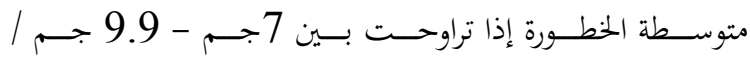

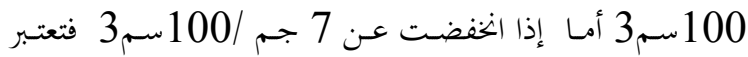

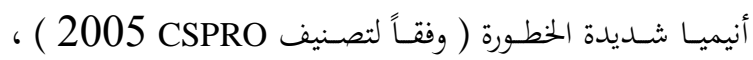
وبناء على ذلك تم التحويل الكمي لمتغير درجة إصابة الأطفال

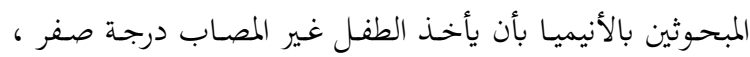

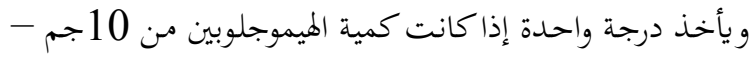

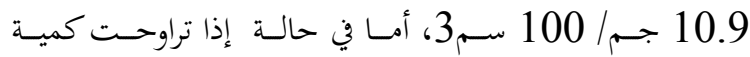
الهيموجلوبين بـين 7 جـم - 9.9 جـم/ 100 سـم3 مـن الـدم فيأخذ درجتين ( مع ملاحظة عدم وجود أي طفل في العينة
لإِحصـائيات وزارة الصـحة والسـكان لسـنة 2006 ) ، وكانست

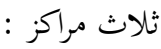
أ - مركز كفر الدوار ثاني ويقع في مدينة كفر الدوار ( ويخدم بعض

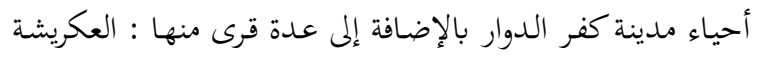
وانطونيادس سيدي شحاتة والتمامة والسناهرة وكفر سليم) 0 ب- مركز كفر الدوار ثالث ، ويقع في قرية البيضـا في أقصى اليمين

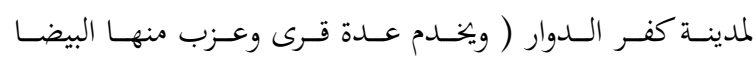

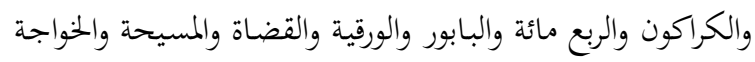

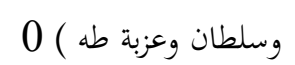

ج - مركز الرعاية بمستشفي سيدي غازي ويقع في قرية سيدي غازي

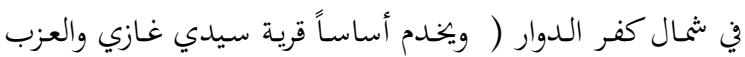

$$
0 \text { (الجماورة لما لمال }
$$

2 - الثاملة والعينة : تمثلت شاملة البحث في جميع الأطفال عمر

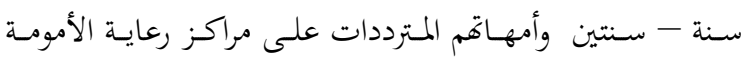
والطفولـة المختـارة خـالال شـهري ينـاير وفبرايـر ســة 2007

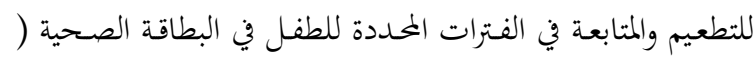
عمر سـنة ، و سـنة ونصف ، وسـنتين ) ، و و بلغ عـدد الشـاملة

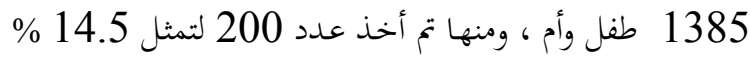

$$
\text { ثنانياً : أسلوب جمع البيانات : } 0
$$

تم جمع البيانات بالمقابلة الشخصية لأمهات الأطفال المبحوثين ، وتم قياس الوزن والطول الحسالي للطفل ، ونسبة الميموجلوبين في الدم

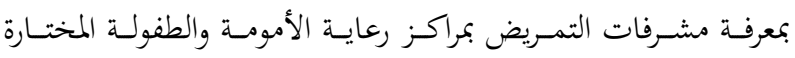

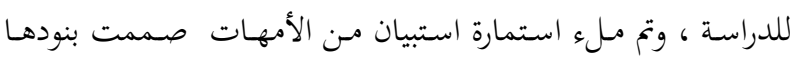

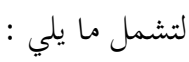

1 - التعـرف على بعضض الخصــائص الشخصـية المميـزة للأطفــال

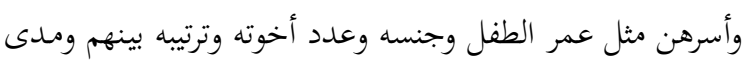

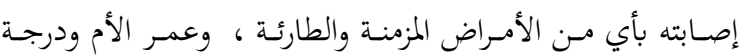

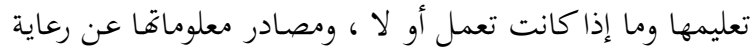

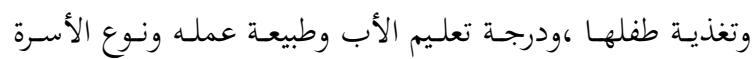
وعدد أفرادها ومصادر الدخل الأسري 0 
ومن 30 سنة إلى أقل من 40 سنة تأخذ ثلاث درجات 0 - -درجة تعليمها : عدم القراءة والكتابة صفر ، قراءة وكتابة 1 درجة

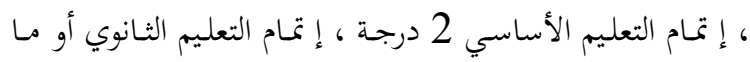
يعادله 3 درجات ، و إ بتمام التعليم العالي 4 درجات 0 -عملها تعمل تأخذ درجة ، و لا تعمل تأخذ صفر 0 - مصـادر معلوماهــا عـن رعايـة وتغذيـة طفلهـا : في حالـة ذكر

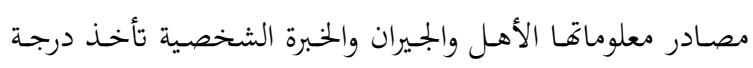
صفر أما في حالة استشارة الطبيب أو متابعة أي برنامج تليفزيوني

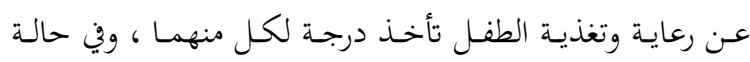
شراؤها لكتب متخصصة وقراءتا تأخذ درجتين 0 -مسـتوى معـارف و مسـتوى ممارسـات الأم فيمـا يتعلـق بتغذيـة طفلها في ذلك العمر : تم قياس كل منهما بعدد عشرون عبارة

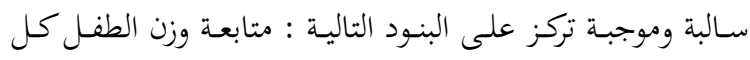

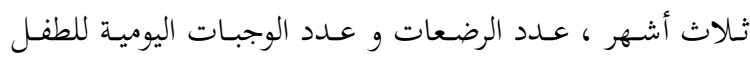

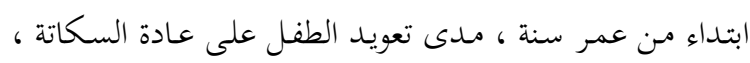

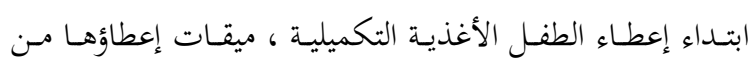

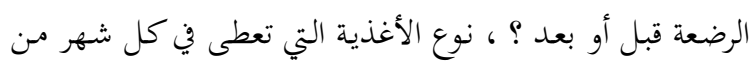

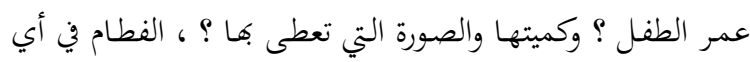

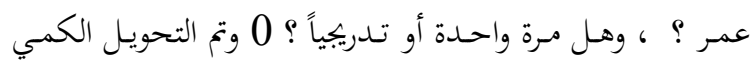

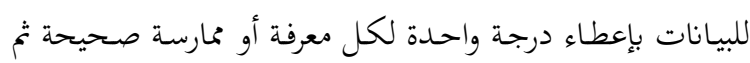

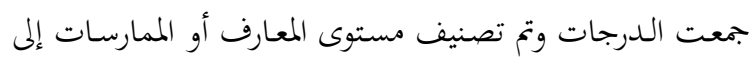
منخفض ومتوسط ومرتفع وفقاً لنسبة الدرجات المعطاة المبحوثة مـن بجموع الـدرجات الكلية الصحيحة ( 20 درجـة ) فإذاذا مـا

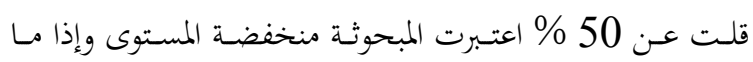
تراوحت درجاهما من 50 - 70 \% من الدرجة الكلية اعتبرت

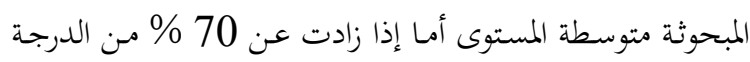

$$
\text { اعتبرت مرتفعة المستوى } 0
$$

\section{ج- متغيرات خاصة بالأب والأسرة :}

- درجـة تعليم الأب : تمح قياسـه تمامـاً مثل درجـة تعليم الأم الذذي سبق ذكره 0 -عدد أفراد الأسرة ، عدد مصادر دخل الأسرة : وضعت الأرقام
انخفضت لديه كمية الهيموجلوبين عن 7 جم ) 2 - المتغيرات المستقلة : أ- متغيرات خاصة بالطفل : -عمر الطفل : قسم إلى فئـات عمر سـنة يأخـذ درجـة واحـدة ، عمر سنة ونصف يأخذ درجتين ، وسنتين ثلاث درجات 0 - عدد أخوته وترتيبه بين أخوته : توضع الأرقام كما هي

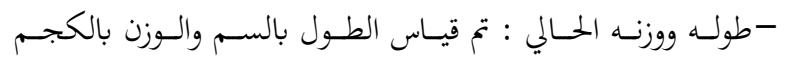

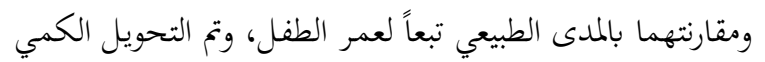

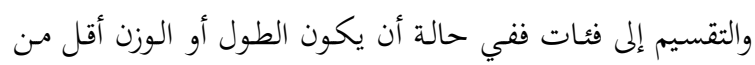

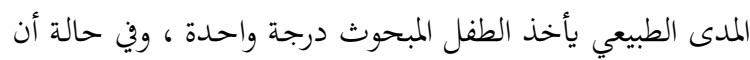

$$
\text { يكونا في المدى الطبيعي يأخذ درجتين } 0
$$

- نمط الاستهلاك الغذائي للطفل ، وتم قياسه باستخدام طريقة تذكر

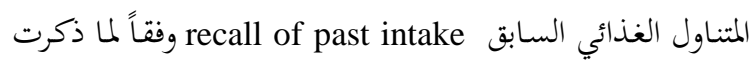

$$
\text { وفاء موسى ( } 1997 \text { ) كما يلي : }
$$

1- المتنـاول اليومي مس المجموعـات الغذائيسة ومقارنتـه للموصي بـه

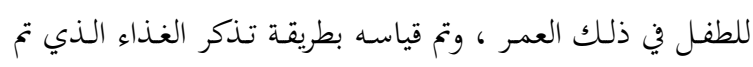

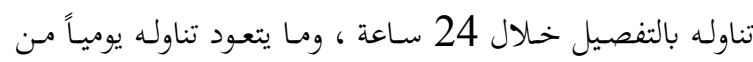

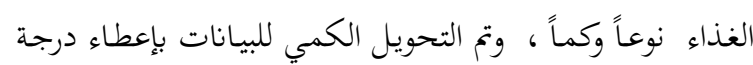
صفر في حالة عدم تناول أي من أغذية المجموعة ، ودرجة واحدة ولمدي في حالة تناول أقل من الموصي به من المجموعة الغذائية ، ودرجتين

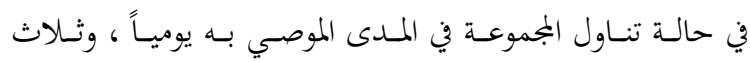

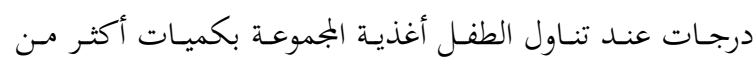

$$
\text { الموصي به } 0
$$

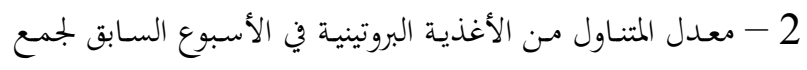

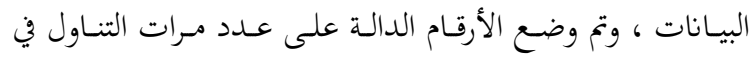

$$
\text { الأسبوع اليسات } 0
$$

3 - عدد مرات تنـاول الشـاي مع أو بعد الوجبة مباشـرة ، وتوضع

$$
\text { الأرقام الخام الدالة على عدد المرات } 0
$$

\section{ب- متغيرات خاصة بالأم : - (بأ}

-عمر الأم : وضعت الأرقام الدالة على الفئات : أقل مـ 20

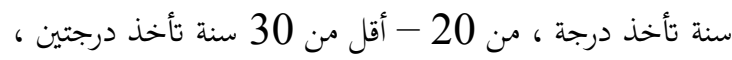




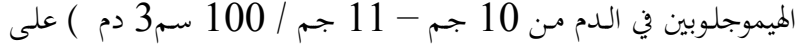

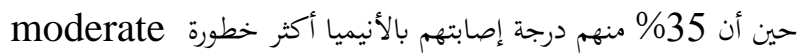

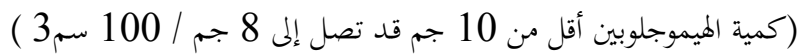

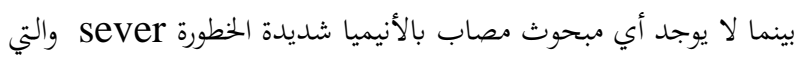

$$
\text { تنخفض بما كمية الهيموجلوبين عن } 7 \text { جم } 0
$$

جدول 1. توزيع الأطفال المبحوثين وفقاً لكمية الميموجلوبين في الدم

\begin{tabular}{|c|c|c|}
\hline$\%$ & العدد & كمية / لهيموجلوبين في الدم 100 سم3 دم \\
\hline 35 & 70 & $9.9-8$ \\
\hline 57 & 114 & $10.9-10$ \\
\hline 8 & 16 & 11 فأكثر \\
\hline 100 & 200 & البجموع \\
\hline
\end{tabular}

ثانياً : تقييم الحالة التغذوية للأطفال المبحوثين من حيث الوزن والطول الحلالي ومقارنتهما بالمدى الطبيعي لأعمارهم :

$$
\text { أظهرت نتائج الدراسة ( جدول 2) ما يلي : }
$$

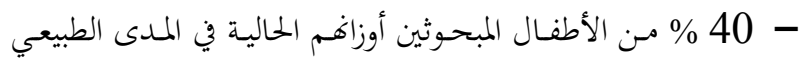

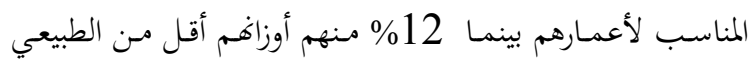

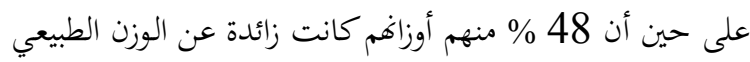

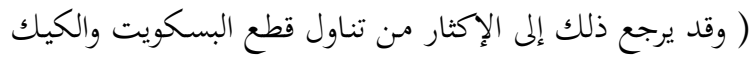
الجاهزة ، وهذا ما أظهرته نتائج الدراسة)

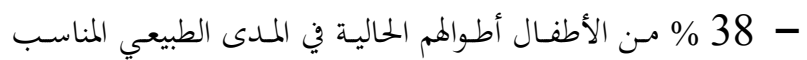

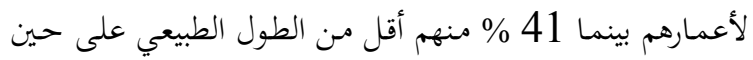

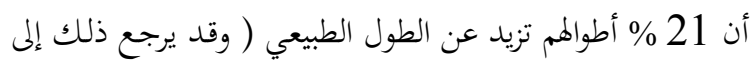

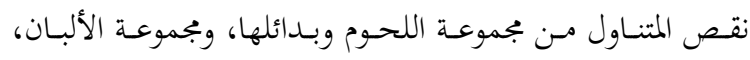
وهذا ما أكدته نتائج الدراسة )

$$
\begin{aligned}
& \text { الدالة على العدد } 0 \\
& \text { رابعاً : التحليل الإحصائي للبيانات : }
\end{aligned}
$$

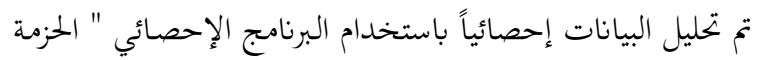

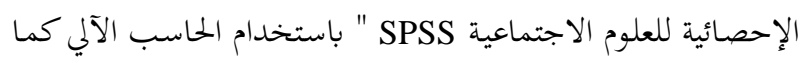
يلي : استخدمت الإحصاء الوصفية كالنسب المئوية والتكرارات

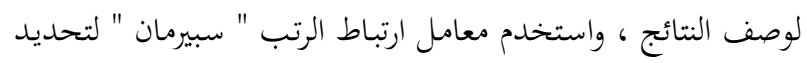

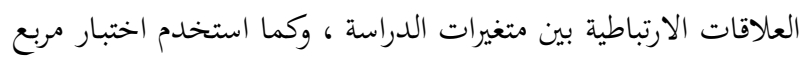

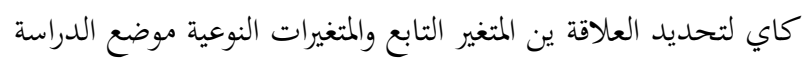

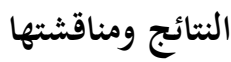

أولاً : درجة إصابة الأطفال المبحوثين بالأيميا :

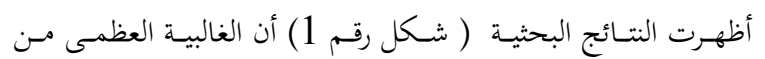

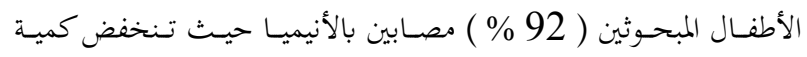
الهيموجلوبين في الدم لديهم عن 11 جم / 100 سم3 من الدم الدم 0

الشكل التوضيحي رقم 1

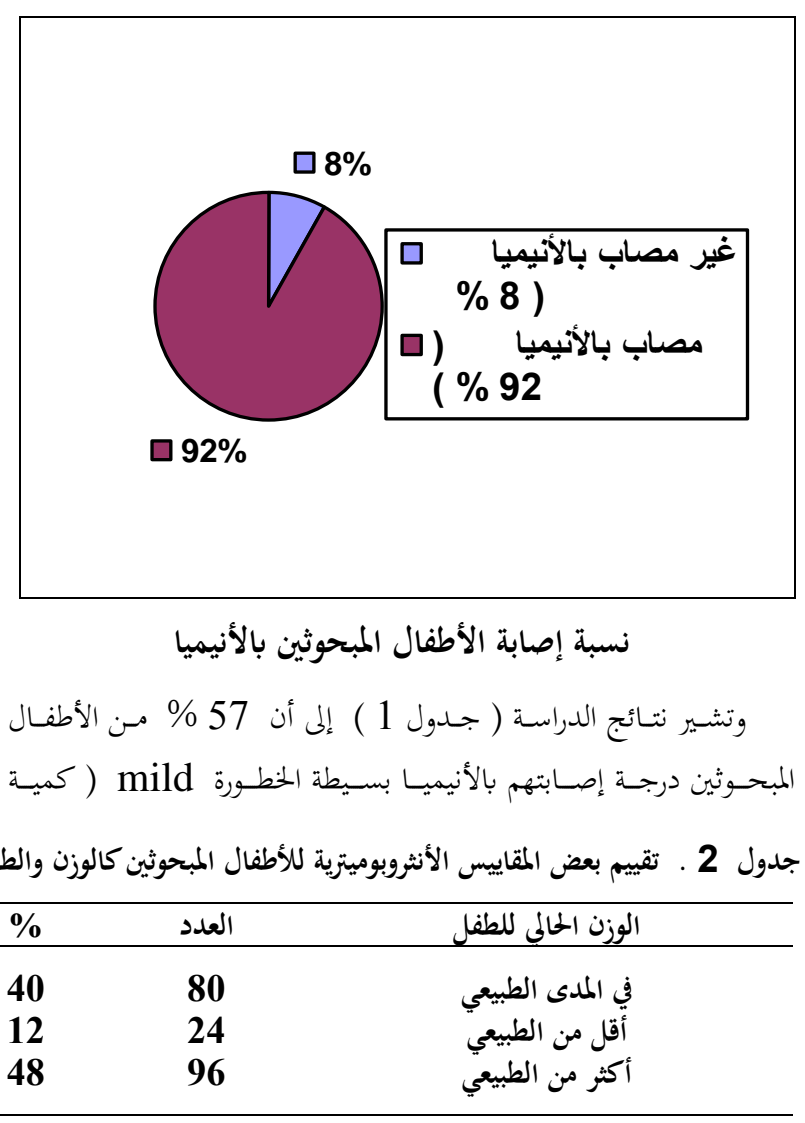




\begin{tabular}{llllll}
\hline $\mathbf{1 0 0}$ & 200 & $\mathbf{1 0 0}$ & 200 & الجمجوع \\
\hline
\end{tabular}

28 -

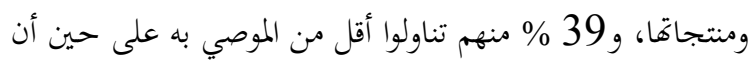

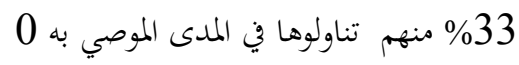

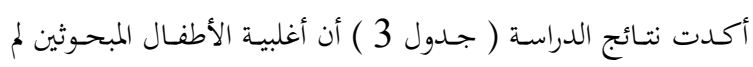

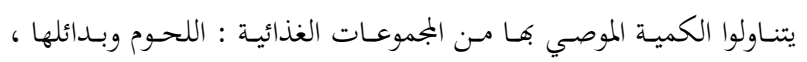

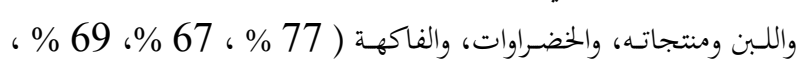
52 \% 52

2- المتنـاول الأسـبوعي مـن الأغذيـة البروتينيـة ( بجموعـة اللحسوم : وبدائلها )

بينت نتائج الدراسة ( غير المجدولة ) أن 13 \% من الأطفال المبحوثين

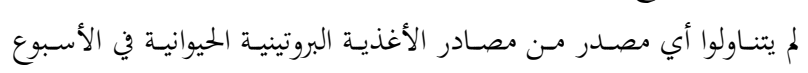

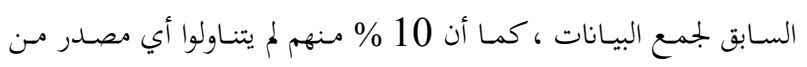
مصادر الأغذية البروتينية سواء حيوانية أو نباتية 0 وعن نوعية الأغذية البروتينية المتناولة أشارت نتائج الدراسة ( جدول 4 )

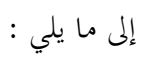
- كانت الأسماك أكثر الأغذية البروتينية استهلاكاً بين الأطفال المبحوثين

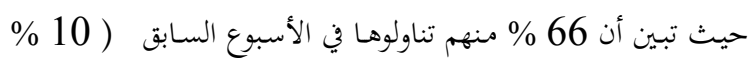

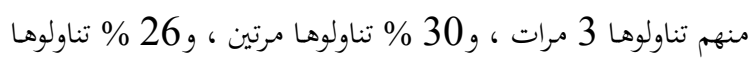

$$
0 \text { مرة واحدة ) مناولما }
$$

ثالثأ : النمط الغذائي للأطفال المبحوثين : 1- الججموعـات الغذائيسة الـتي يتناولهـا الأطفـال المبحسوثين يوميـاً ومقارنتها بالموصي به لأعمارهم :

$$
\text { أظهرت النتائج البحثية (جدول 3) ما يلي : }
$$

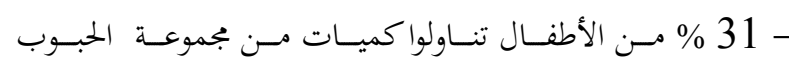
ومنتجاتا أقل من الموصي به يومياً بينما 56\% من منهم تناولوها في

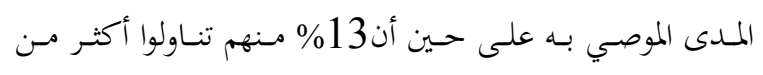

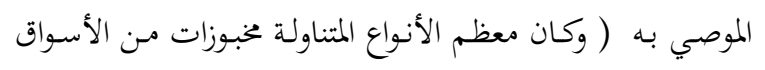
0 كالكيك والبسكويت

- 23\% من الأطفال لم تناولوا بجموعة اللحوم وبدائلها بأي كمية في

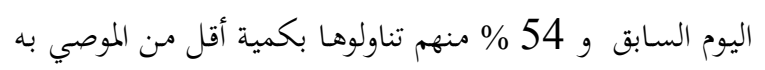
على حين أن 23 \% منهم تناولوها بالكمية الموصي بها 0 - 47 \% من الأطفال لم يتناولوا أي كمية مـن الخضراوات في اليوم

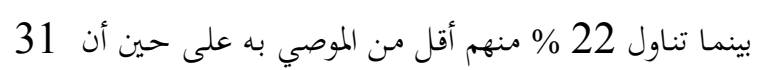

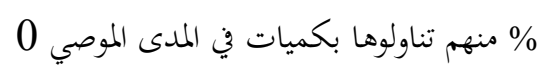

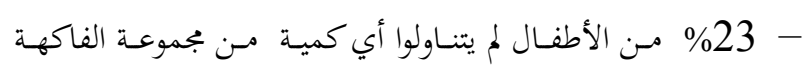

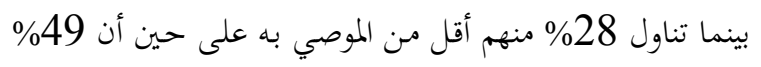

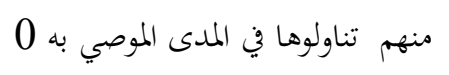

جدول 3 ـ توزيع الأطفال وفقاً للمجموعات الغذائية المتناولة يومياً ومقارنتها بالموصي به لأعمارهم

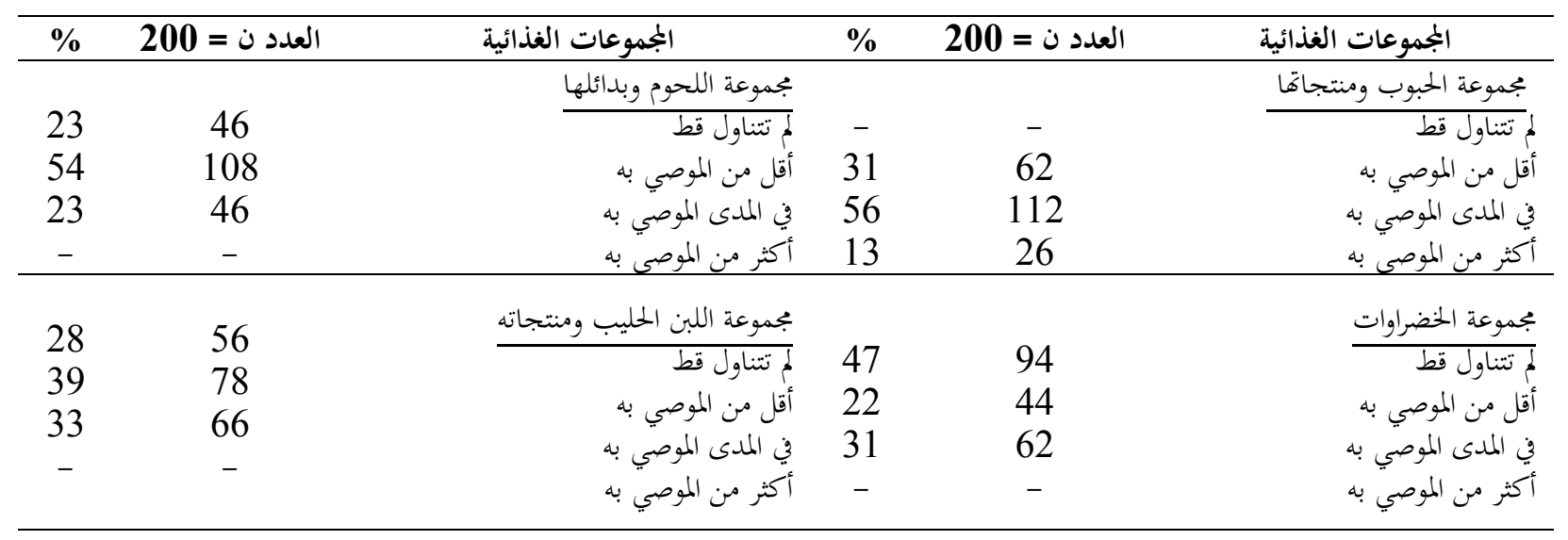




\begin{tabular}{|c|c|c|c|c|c|c|c|c|c|c|}
\hline & & & & & & & $\begin{array}{c}23 \\
28 \\
49 \\
- \\
\end{array}$ & & & 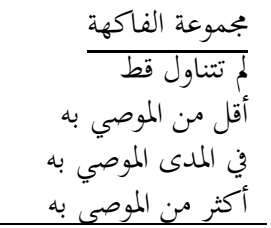 \\
\hline \multicolumn{11}{|c|}{ جدول 4 . توزيع الأطفال وفقاً لمعدل تناول مجموعة اللحوم وبدائلها في الأسبوع السابق لجمع البيانات } \\
\hline \multicolumn{10}{|c|}{ معدل تناولها في الأسبوع السابق لجمع البيانات } & \multirow{3}{*}{ 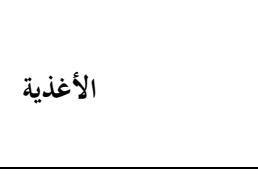 } \\
\hline \multicolumn{2}{|c|}{ 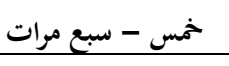 } & \multicolumn{2}{|c|}{ 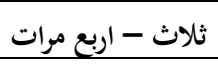 } & \multicolumn{2}{|c|}{ مرتين } & \multicolumn{2}{|c|}{ مرة واحدة } & \multicolumn{2}{|c|}{ لم لميتاوها قط } & \\
\hline$\%$ & 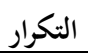 & $\%$ & 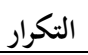 & $\%$ & 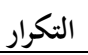 & $\%$ & 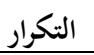 & $\%$ & 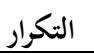 & \\
\hline- & - & 1 & 2 & 14 & 28 & 22 & 44 & 63 & 126 & 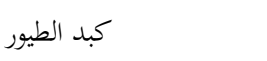 \\
\hline- & - & 2 & 4 & 19 & 38 & 28 & 56 & 51 & 102 & ل ل الحم الطيور \\
\hline- & - & 3 & 6 & 19 & 38 & 21 & 42 & 57 & 114 & 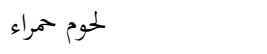 \\
\hline- & - & 10 & 20 & 30 & 60 & 26 & 52 & 34 & 68 & 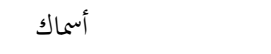 \\
\hline 7 & 14 & 17 & 34 & 15 & 30 & 8 & 16 & 53 & 106 & بيض \\
\hline 17 & 34 & 6 & 12 & 9 & 18 & 18 & 36 & 41 & 82 & فول \\
\hline- & - & - & - & 5 & 10 & 19 & 38 & 76 & 152 & عدس \\
\hline
\end{tabular}

رابعاً : قياس وعي وممارسات الأمهات بتغذية أطفالهن منذ الولادة حتى العمر الحالي :

1 - مستوى معارف الأمهات لبعض البنود الخاصة بتغذية طفلها:

$$
\text { أشارت النتائج البحثية ( جدول 5) إلى أن } 53 \text { \% }
$$

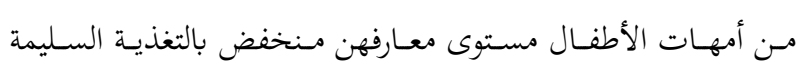

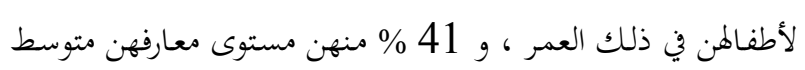

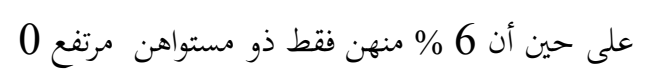

وأوضحت نتـائج الدراسـة ( غير الججدولة ) أن أكثر البنـود عـدم

$$
\text { معرفة من جانب الأمهات كانت كما يلي : }
$$

- 89 \% من الأمهات لا يعرفن أن الطفل بعد عمر سنة يبـب أن

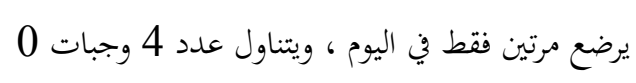

- 79 \% لا يعـرفن بــدء إعطــاء الطفـل لصـفار البـيض والبيضــة

الكاملة0

- 69 \% لا يعـرفن بــــ إعطـاء الطفـل اللحسوم الحمـراء والطيـور ،

$$
\text { والكمية، والصورة التي تعطى بها } 0
$$

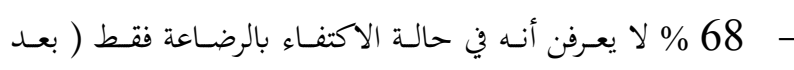
بلوغه عمر 6 شهور ) يمكن أن يضعف الطفل ويصيبه بالأمراض
- يليها الفول المدمس حيث تناوله 59 \% من الأطفال ( 17 \% 0 منهم تناولوه بمعدل من 5 - 7 مرات في الأسبوع ) ملتوله - وتنـاول لحوم الطيور 49\% مـن الأطفـال ( 19\% منهم تناولوهـا مرتين في الأسبوع و28\% تناولوها مرة واحدة ) 0 - كما تناول 47\% من الأطفال البيض (23 \% منهم تناولوه بمعدل

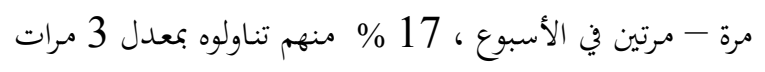

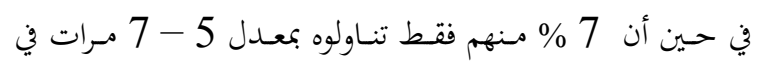

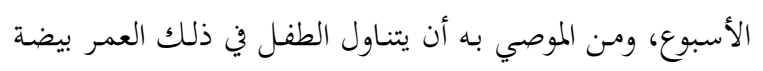
يومياً كمصدر للبروتين والحديد عالي الجودة ) 3 - عدد مرات تناول الطفل للشاي أثناء أو بعد الوجبة مباشرة: أظهرت نتائج الدراسة ( غير المجدولة ) أن 52 \% من الأطفال

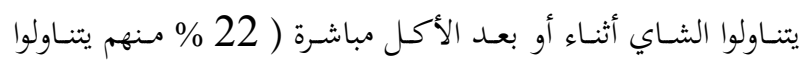

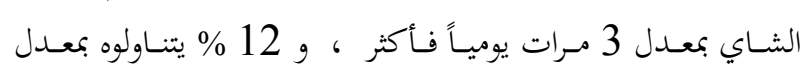

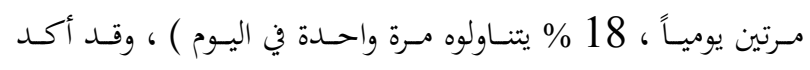
أحدالع Verster أحد العوامل المسببة لأنيميا نقص الحديد خاصة في الدول النامية لأنه

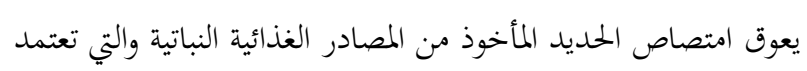
عليها الأفراد خاصة في الدول النامية 0 
فقط من الأمهات أعطت الطفل الخضراوات أو الفاكهة في الوقت الموصي به إلا أن جميعهن لم تراعي الصورة والكمية التي يعطى بها

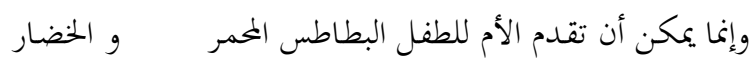

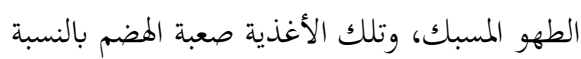
لإمكانية الجهاز الهضمي للطفل في ذلك العمر 0 -60\% من الأمهات لمُ تعط الطفل صفار البيض قبل بلوغه سنة

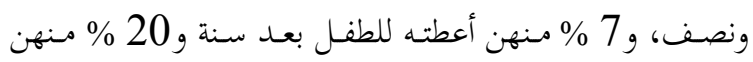

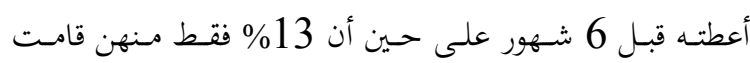
بالممارسة السليمة بإعطاء الطفل صفار البيض في عمر 6 شهور 0 - 47\% من الأمهات لم تعط الطفل بيضة كاملة قبل بلوغه سنة ونصف ، 27 \% أعطته بيضة كاملة بعد سنة، و 18 \% \% أعطته

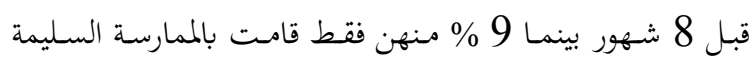
بإعطائه بيضة كاملة عند بلوغه 8 شهور 0 41-

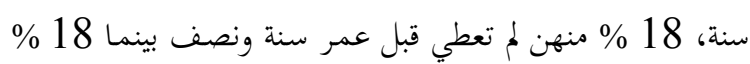

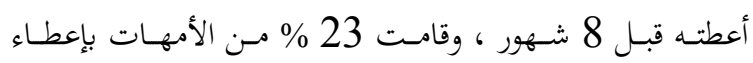

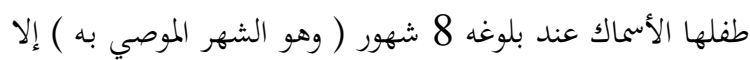

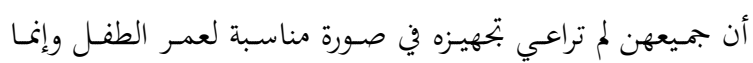

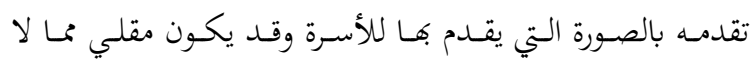

$$
\text { يناسب القدرة المضمية للطفل } 0
$$

-42 مـ الأمهات لم تعط كبد الطيور للطفل قبل بلوغه عمر

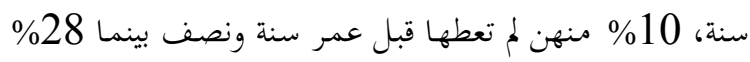

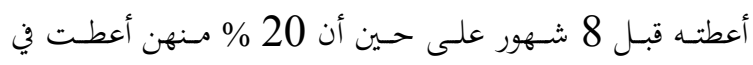

$$
\text { الشهر الموصي به ( الشهر الثامن ) }
$$

35 \% مـ الأمهات لم تعط الطفـل اللحوم الحمـراء قبل بلوغـه عمر سنة ونصف ، 40 \% منهن لم تعطها قبل عمر سنة بينما 15 \% أعطتهـ قبـل 9 شهور على حين أن 10 \% ف فقط منهن أعطت اللحوم ابتداء من الشهر الموصي به ( الشهر التاسع ) 0
-64 \% لا يعرفن أنه مـن الأفضل عند إعطاء الأغذية التكميلية

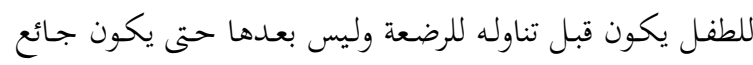

$$
\text { فيقبل على الطعام ولا يرفضه } 0
$$

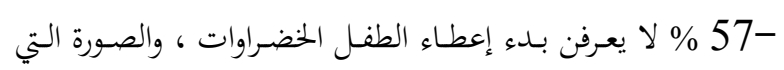

$$
0 \text { يعطى بها } 0
$$

2 - مستوى ممارسـات الأمهات الخاصـة بتغذيـة الطفل المبحوث منذ ولادته حتى العمر الحالي : أظهرت نتائج الدراسة ( جدول 5 ) أن 60 \% من أمهات الأطفـال مسـتوى ممارستهن للممارسـات المتعلقــة بالتغذيـة السـليمة

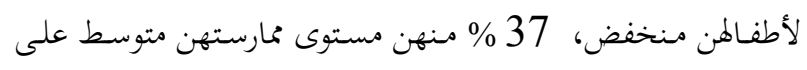

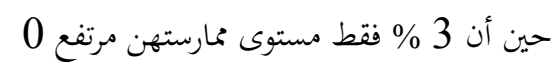
وأشـارت نتائج الدراسـة ( غير المجدولة ) إلى بعض الممارسات الحاطئة التي أتبعتها الأمهات المبحوثات في تغذية أطفالهن فيما يلي:

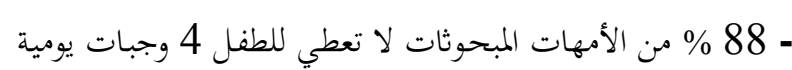

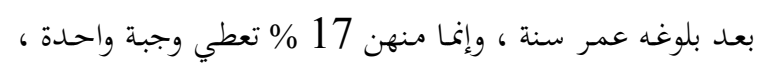

$$
\text { و } 27 \text { \% تعطي وجبتين } 0
$$

-75 -75 من الأمهات لا تحدد عدد الرضعات اليومية للطفل وإنما

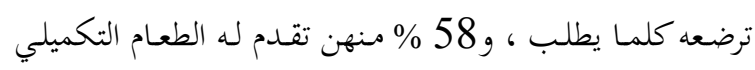

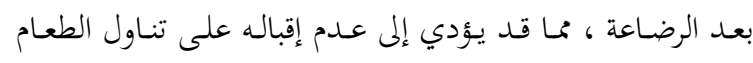

$$
\text { المقدم له } 0
$$

-54 \% منهن لم تبدأ إعطاء الطفل الأغذية التكميلية مع الرضاعة

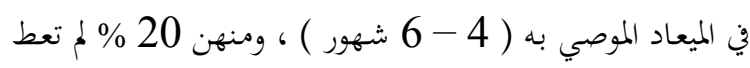

$$
\text { الأغذية إلا بعد عمر سنة } 0
$$

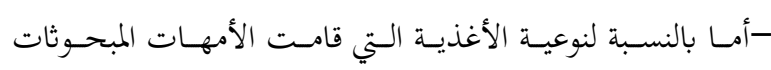

\begin{tabular}{|c|c|c|c|c|c|}
\hline$\%$ & العدد العد & مستوى ممارسة الأمهات & $\%$ & العدد & مستوى معارف الأمهات \\
\hline
\end{tabular}

$$
\text { بإعطائها للطفل بينت النتائج ما يلي : }
$$

-جميع المبحوثات لا تجهز وجبة خاصة للطفل تبعاً لعمره وإنما تقدم للطفل ما تتناوله الأسرة من غذاء بكمية بسيطة 0

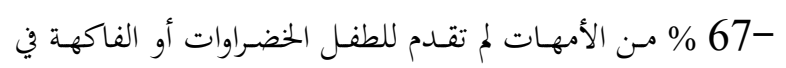

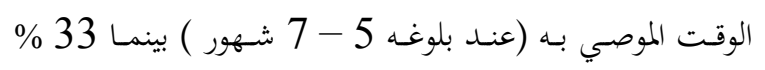

جدول 5 . توزيع الأمهات المبحوثات وفقاً لمستوى معارفهن وممارساتن للتغذية السليمة لأطفالهن 


\begin{tabular}{|c|c|c|c|c|c|}
\hline 60 & 120 & منخفض ( أقل من 50 \% ) & 53 & 106 & منخفض ( أقل من 50 \% ) \\
\hline 37 & 74 & متوسط ( 50 \%- أقل من 70 \% ) & 41 & 82 & متوسط ( 50 \% - أقل من 70 \% ) \\
\hline 3 & 6 & مرتفع ( 70 \% فأكثر ) & 6 & 12 & مرتفع ( 70 \% فأكثر ) \\
\hline 100 & 200 & البموع اعو & 100 & 200 & المجموع \\
\hline
\end{tabular}

أو 2 خـوخ مسـلوق ، أمـا بالنسبة للشـهر الثـامن فيضـاف لأغذيـة الشهر السابع قطعة في حجم نصف البيضة من كبدة الدجاج المسلوقة

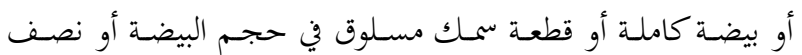
كوب لبن صغير ، وين الشهر التاسع يمكن إعطاء الطفل لحوم الدجاج بدلاً من كبدةا ( قطعة في حجم البيضة الكبيرة )، كما يمكن إعطائه

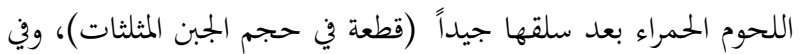

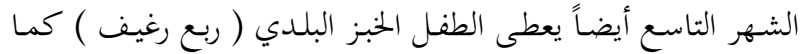
يمكن إعطائه الفول المدمس بمقدار ملعقة كبيرة 0 خامساً : بعض الخصائص الشخصية والأسرية المميزة للأطفال المبحوثين وأسرهن : أشارت نتائج الدراسة ( جدول 6 ) ) إلى ما يلي : - 56 \% من الأطفال المبحوثين كانوا من الذكور مقابل 44 \% من الإناث - 67 \% من الأطفال أعمارهم سنة ونصف على حين أن 26 \%

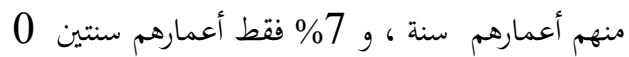
- 37 \% من الأطفال ليس لديهم اخوة ، و50 \% منهم لديهم أخ واحد أو أثنين بينما 13 \% لديهم من 3 - 4 اخوة ليس 0 - 38 \% من الأطفال ترتيبهم الأول ، و 26 \% منهم ترتيبهم الثاني،

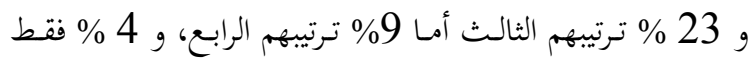

$$
\text { ترتيبهم الخامس بين الأخوة } 0
$$

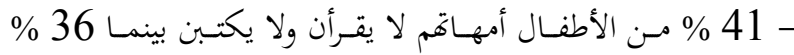

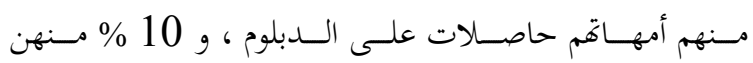
حاصلات على الشهادة الجامعية 0 - الغالبية العظمى من الأمهات ( 93 \% ) لا يعملن خـارج المنزل مقابل 7 \% منهن يعملن خارج المنزل 0
-65 \% من الأمهات لم تعط الطفل لحوم الطيور قبل عمر سنة ،

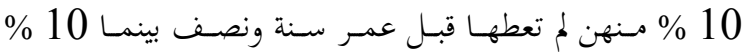

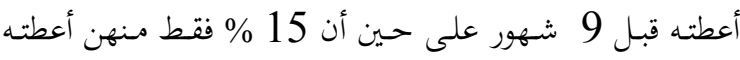

$$
\text { لحوم الطيور بدأ من الشهر التاسع } 0
$$

ودلـت النتـائج السـابقة على عـدم اتبـاع الغالبيـة العظمى مـن

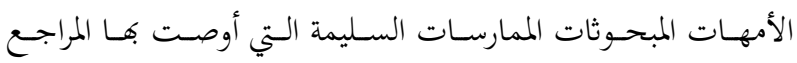
والدراسات بخصوص تغذية الطفل الرضيع حتى عمر سنتين - فقد ذكرت رفيدة حسين ( 1997 ) أن الطفل عمر سنة يجب أن يأخذ عدد 2 رضعه فقط وعدد 4 وجبات غذائية متنوعة تشمل المجموعات رقدات الغذائية الموصي بها وإلا تعرض الطفل للإصابة بأمراض سوء التغذية )

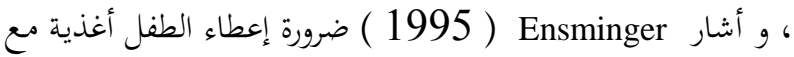
الرضـاعة ابتـاء مسن الشـهر الرابع كـالحبوب والبقـول المسـلوقة لمـده

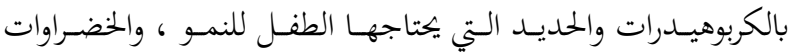
والفاكهـة المقشـرة والمهروسـة لمد الطفل بالفيتامينـات والمعادن اللازمـة

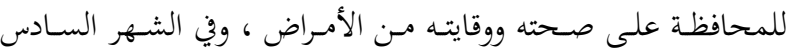
يعطى صفار البيض لتزويد الطفل بالحديد والبروتين ، ويعطى بجموعة

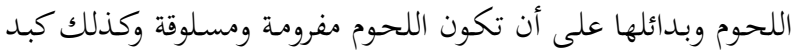
الدجاج والأسماك تسلق جيداً وقهرس مع مراعاة عدم إضافة سمـن في

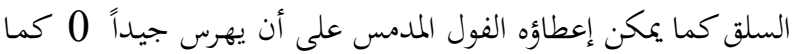
أكد معهد التغذية بجمهورية مصر العببة ( 1996 ) إلى بداية إعطاء الطفل الأغذية عند بلوغه الشهر الخامس بإعطائه نصف كوب عصير

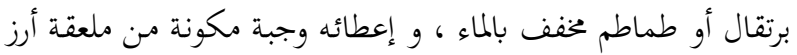
مسلوق وملعقة عدس مسلوق مع إضافة ربع ملعقة طحينة ، وإعطاء

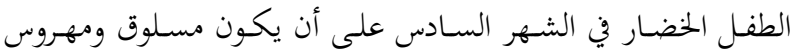
بمقدار 2 ملعقة كبيرة كما يعطى الطفل في نفس الشهر نصف صفار بيضة ونصف كوب زبادي أو قطعة جبن مثلثات ، وفي الشهر السابع يستبدل عصير الفاكهة بالفاكهة الكاملة بمقدار نصف موزة مهروسة 
مُجَّمَي في دراستها ( 2004 ) بأنـه كلمـا قـل وزن الطفـل عـن الطبيعي زادت درجة إصابته بالأنيميا 0 - وجـدت علاقة عكسية معنويـة عند مستوى معنويـة 0.01 بـين درجة إصابة الطفل المبحوث بالأنيميا وبين تناوله الحصة اليومية الموصي بها من المجموعات الغذائية كما

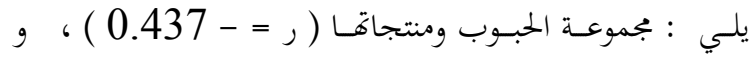
مجموعة اللحوم وبـدائلها ( ر = - 0.297 ) ) ، و مجموعة اللبهوبن ومنتجاته ( ر= - 0.285 ) ) ، و مجموعة الفاكهة - 0.249 ) و مجموعة الخضراوات ( ر = - 0.244 ) - وجـدت علاقة عكسية معنويـة عند مستوى معنويـة 0.01 بين

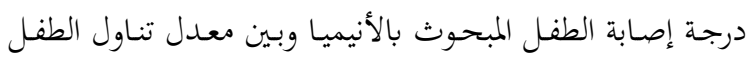

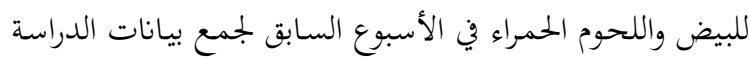

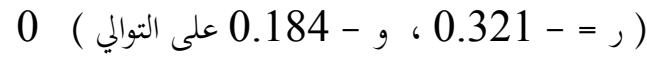
- وجـدت علاقة عكسية معنويـة عند مستوى معنويـة 0.01 بين درجة إصابة الطفل المبحوث بالأنيميا وبين درجة تعليم الأم

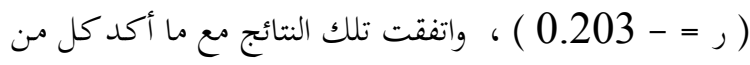

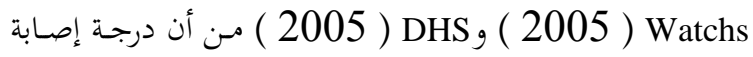
الطفل بالأنيميا تزيد بين الأمهات غير المتعلمات 0
- 49 \% من الأمهات مصادر معلوماهن عن تغذية أطفالهن مصادر غير رسمية ( الأهل والجيران والخببرة الشخصية ) على حين أن 51

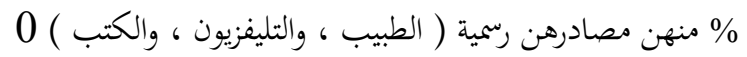
- 38 \% من الأطفال آبائهم لا يقرأن ولا يكتبن بينما 41 \% مـ

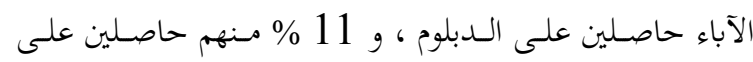
الشهادة الجامعية 0 - نوع الأسرة لدى 57 \% مـ الأطفال أسرة غير بسيطة مقابل 43 \% أسرهن بسيطة 0

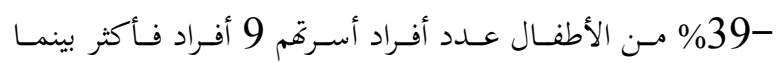

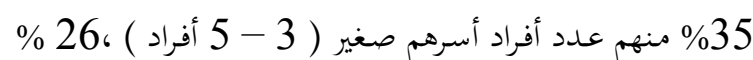
منهم أسرهم من 6 - 8 أفراد 0 سادساً : التحليل الإحصائي للنتائج البحثية لتحديد العلاقات بين

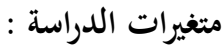
1- باستخدام معامل ارتباط الرتب " سبيرمان " لتحديد العلاقات الارتباطية

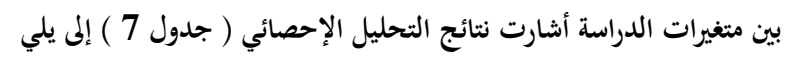
- وجـدت علاقة عكسية معنوية عند مستوى معنوية 0.01 بين

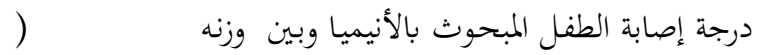

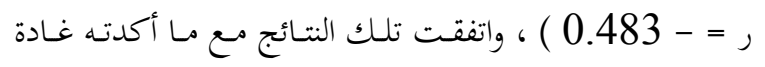

جدول 6 . توزيع الأطفال وفقاً لبعض الخصائص الشخصية والأسرية

\begin{tabular}{lllll}
\hline$\%$ & $\%$ & $200=0$ \\
\hline
\end{tabular}




\begin{tabular}{|c|c|c|c|c|c|}
\hline $\begin{array}{c}93 \\
7\end{array}$ & $\begin{array}{c}186 \\
14\end{array}$ & تعمل تعمل الأم بأجر : & $\begin{array}{l}56 \\
44\end{array}$ & $\begin{array}{c}112 \\
88\end{array}$ & نوع ألنفل : \\
\hline $\begin{array}{l}51 \\
49\end{array}$ & $\begin{array}{c}102 \\
98\end{array}$ & 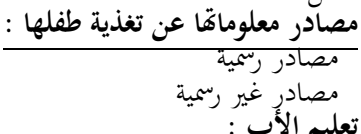 & $\begin{array}{c}26 \\
67 \\
7\end{array}$ & $\begin{array}{c}52 \\
134 \\
14\end{array}$ & سنة سنة ونصف الطعل بالسنه : \\
\hline $\begin{array}{c}38 \\
1 \\
9 \\
41 \\
11\end{array}$ & $\begin{array}{l}76 \\
2 \\
18 \\
82 \\
22\end{array}$ & 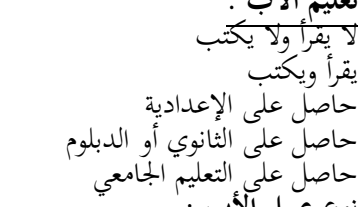 & $\begin{array}{l}37 \\
50 \\
13\end{array}$ & $\begin{array}{l}74 \\
100 \\
26 \\
76\end{array}$ & 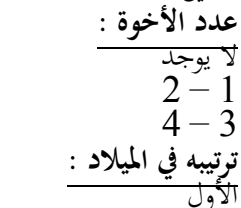 \\
\hline $\begin{array}{l}16 \\
37 \\
28 \\
15 \\
4\end{array}$ & $\begin{array}{c}32 \\
74 \\
56 \\
30 \\
8\end{array}$ & 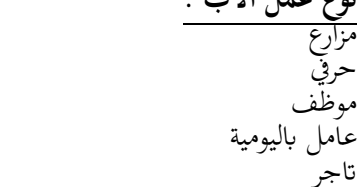 & $\begin{array}{c}26 \\
23 \\
9 \\
4\end{array}$ & $\begin{array}{c}52 \\
46 \\
18 \\
8\end{array}$ & 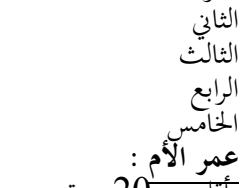 \\
\hline $\begin{array}{l}43 \\
57\end{array}$ & $\begin{array}{c}86 \\
114\end{array}$ & غوعير بسيطة الأسرة : عبسة & $\begin{array}{c}8 \\
63 \\
29\end{array}$ & $\begin{array}{c}10 \\
126 \\
58\end{array}$ & 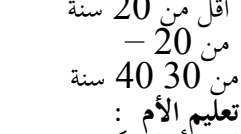 \\
\hline $\begin{array}{l}35 \\
26 \\
18 \\
21\end{array}$ & $\begin{array}{l}70 \\
52 \\
36 \\
42\end{array}$ & 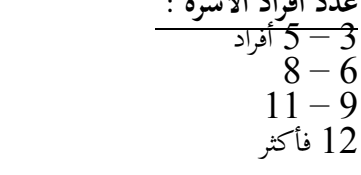 & $\begin{array}{c}41 \\
4 \\
9 \\
36 \\
10\end{array}$ & $\begin{array}{c}82 \\
8 \\
18 \\
72 \\
20\end{array}$ & 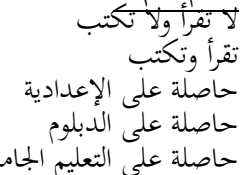 \\
\hline
\end{tabular}

- وجدت علاقة طردية معنوية عند مستوى معنوية 0.05 بين درجة

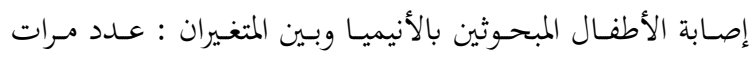

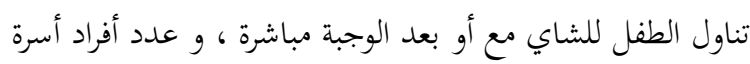

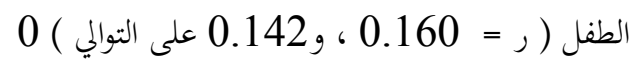

- لم توجـد أي علاقة ارتباطيه معنويـة بين درجـة إصابة الطفل المبحوث

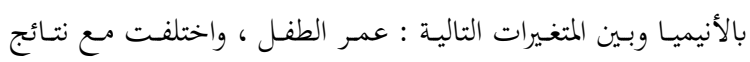
Ghoneim

$$
\text { عمر الطفل تقل إصابته بالأنيميا } 0
$$

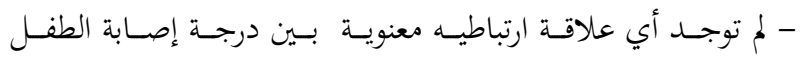

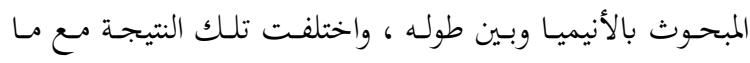

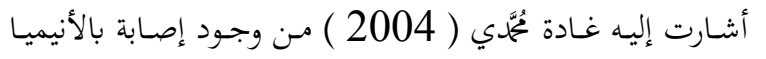

$$
\text { بين الأطفال قصار القامة عن ذوي الطول الطبيعي }
$$

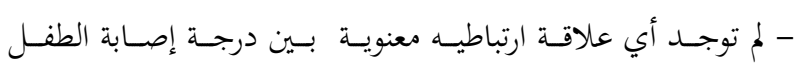

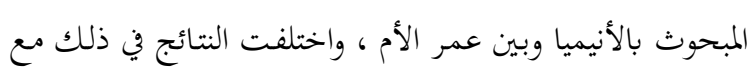

- وجـدت علاقة عكسية معنويـة عند مستوى معنوية 0.01 بين درجة إصابة الطفل المبحوث بالأنيميا وبين مستوى ممارسة الأم

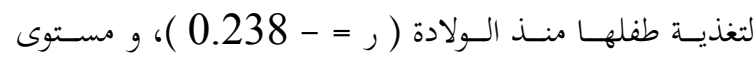

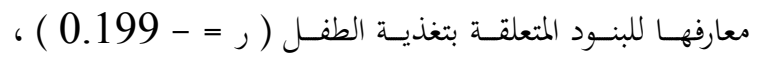

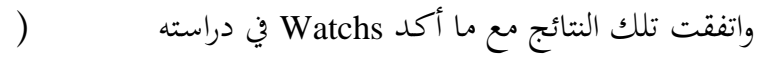
2005 ) من وجود علاقة معنوية إيجابية بين مستوى معلومات

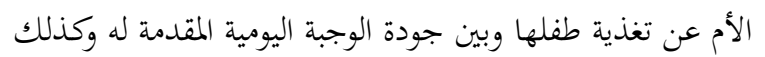
بين تركيز الهيموجلوبين في دمه - وجــت علاقـة عكسية معنويـة عنـــ مسـتوى معنويـة 0.05 بـين

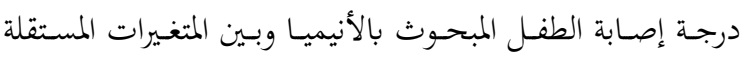

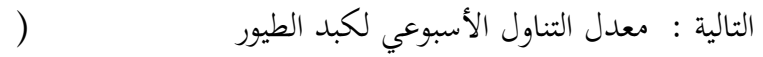

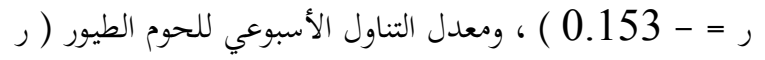

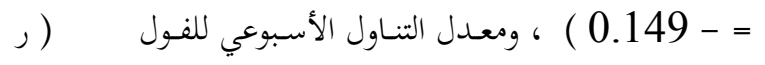
$0(0.164-=$ 
- عدم وجود علاقة معنوية بين درجة إصابة الطفل بالأنيميا وجنس الطفل

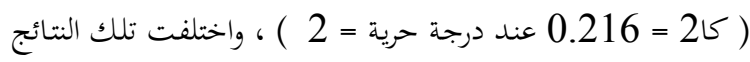

مع مـا أظهرته DHS ( 2005 ) مـن أن إصابة الأطفال بالأنيميا

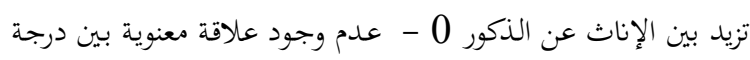

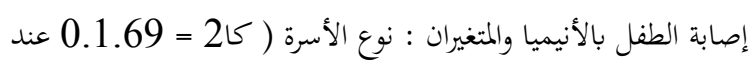

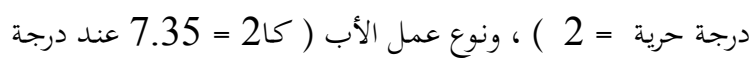

$$
\text { حرية }
$$

مـا أظهرته DHS DS 2005 ) مـن وجـود علاقة بين عمـر الأم ودرجة إصابة الطفل بالأنيميا حيث تقل بزيادة عمر الأم 0

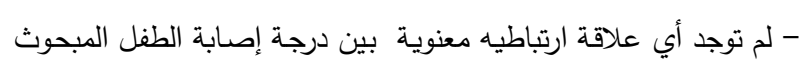

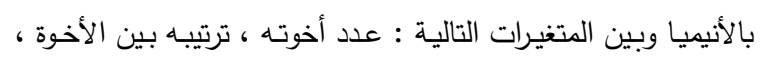

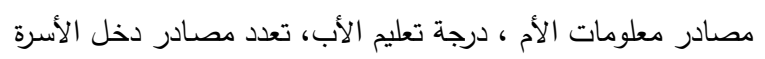
0

2 - باستخدام اختبار مربع كـاي لاختبار العلاقة بين درجـة إصابة الطفل بالأنيميا وبين المتغيرات الأسمية بينت النتائج ما يلي :

جدول 7 ـ العلاقات الارتباطية بين درجة إصابة الأطفال المبحوثين بالأنيميا الغذائية والمتغيرات المستقلة المدروسة

\begin{tabular}{|c|c|c|c|}
\hline قيم معامل الارتباط & المثغيرات المستقلة & قيم معامل الارتباط & المتغيرات المستقلة \\
\hline *0.153- & معدل تناول كبد الطيور أسبوعياً & 0.052 & عمر الطفل \\
\hline *0.149 - & معدل تناول لحوم الطيور أسبوعياً & ***0.483 - & وزن الطفل \\
\hline $0.092-$ & معدل تناول الأسماك أسبوعياً & $0.078-$ & طول الطفل \\
\hline *0.164- & معدل تناول الفول أسبوعياً & 0.067 & عدد الأخوة \\
\hline $0.053-$ & عمر الأم & 0.069 & ترتيبه بين أخوته \\
\hline ** 0.203 - & درجة تعليمها & ***0.437 - & المثناول اليومى من الحبوب ومنتجاها \\
\hline ** 0.199 - & مستوى معارفها & *** $0.244-$ & المتناول اليومى من الخضراوات \\
\hline $0.057-$ & مصادر معلوماتما عن تغذية طفلها & *** $0.249-$ & المتناول اليومي من الفاكهة \\
\hline *** $0.238-$ & مستوى ممارستها في تغذية طفلها & *** 0.297 - & المتناول اليومى من اللحوم وبدائلها \\
\hline $0.072-$ & درجة تعليم الأب " & *** $0.285-$ & المتناول اليومى من اللبن ومنتجاته \\
\hline *0.142 & علدد أفراد الأسرة & *0.160 & عدد مرات تناول الشاي مع أو بعد الوجبة \\
\hline $0.049-$ & عدد مصادر دخل الأسرة & *** $0.321-$ & معدل تناول البيض أسبوعياً \\
\hline & & $0.184-$ & معدل نناول الدحوم اخمراء اسبو \\
\hline
\end{tabular}

5- وفاء موسى ( 1997 ) 0 قياس الحالة التغذوية في المجتمع 0 الغذاء

والتغذيـة 0 الكتـاب الطبي الجـامعي 0 منظمـة الصـحة العالميـة 0

$$
\text { أكاديميا }
$$

6-COPC (2005) . Application of Community Oriented Primary Care at El Nakhas Village - Anemia at El Nakhas Faculty of Medicine, Department of Community Environmental \&Occupational Medicine. Zagazig University .

7-Coyer, S. M. ( 2005) . Anemia Diagnosis and Management . Journal of Pediatric Health Care 19 (6) p : 380 - 385 .

8-CSPRO (2005) . Nutritional Status and Anemia Level . www.cspro.org/pubs/pdf/FR 176/

9-DHS databases (2005). Nutritional Status and Anemia Levels . www. Measuredhs . com / pubs / pdf / FR / 176 / 14 chapter .

10-El Masry, A. M. (2003). Parasitic infection and malnutrition in rural pre - school children in northen Nile Delta area , Egypt . Bulletin of High Institute of Public Health 33 (2).

$$
\begin{aligned}
& \text { المراجع } \\
& \text { 1- رفيـدة حسـين خاشـقجي ( } 1997 \text { ) } 0 \text { تغذيـة الرضـع وصـغار } \\
& \text { الأطفال0 الغذاء والتغذية } 0 \text { الكتاب الطبي الجامعي } 0 \text { منظمة الصحة } \\
& \text { العالمية } 0 \text { أكاديميا } 0 \\
& \text { 2- غادة عُمَّدي إبراهيم الخرباوي ( } 2004 \text { ) } 0 \text { تأثير أنيميا نقص الحديد } \\
& \text { على النمو الجسماني والمعري لأطفال الحضر } 0 \text { قسم الاقتصاد المننزي } 0 \\
& \text { كلية الزراعة } 0 \text { جامعة القاهرة } 0 \\
& \text { 3- معهد التغذية ( } 1996 \text { ) } 0 \text { دليل الغذاء الصحي للأسرة المصرية } 0 \\
& \text { جمهورية مصر العربية } 0
\end{aligned}
$$

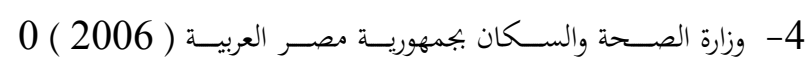

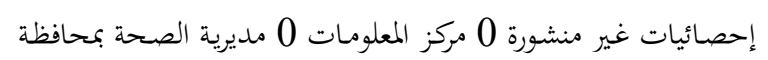

$$
\begin{aligned}
& \text { البحيرة } 0
\end{aligned}
$$


15- Wachs, T . D., Kanashiro, H. C., Cueto, S. and Jacoby , E . ( 2005 ) . Maternal Education and Intelligence Predict Offspring Diet and Nutritional Status. The American Society for Nutritional Sciences . J . Nutr . 135 P: 2179 2186, September .

16 -WHO (1996). Guidelines for the Control of Iron Deficiency .WHO. Printed by Bafra Graphics , Alexandria , Egypt .

17- Zlotkin, S. (2003) .Clinical nutrition: 8 The role of nutrition in the preventation of iron deficiency anemia in infants, children and adolescents .CMAJ 168 (1) P : 5 .
11-Ensminger, M. E. ; Ensminger . A., Konland, J. E. and Rabson J. R. K. (1995). The Concies Encyclopedia of Food and Nutrition. CRC press . inc .

12-Ghoneim , E. H . and Ahmed, M. H. (2000) . prevalence of iron deficiency anemia among pre- school children in Alexandria . Bulletin of High Institute of Public Health 30 (4) .

13- Fouda, A. Elbadawy, A. and Aboserea M . ( 2004) . Anew Teaching Approach at Tarout Village . http: // ictp. $\mathrm{zu}$.edu.eg.

14-Verster , Anna . (1996). Guidelines for the Control of Iron Deficiency in Countries of the Eastern Mediterranean Middle East and North Africa . WHO . EM / NUT / 177, E/G/11.96 .

\title{
ABSTRACT \\ Anemia Among one to two years Rural Children and its Relationship with some Variables in some Villages in Khafer EI Dawar in Behera Governorate
}

\author{
Amal el Sayed el Asaal
}

\section{This study aimed to :}

1- determine the degree of anemia among children

2- respondents assessment of the nutritional status of the respondents children by measuring their weights and their lengths .

3 -studing their daily dietary pattern .

4-determine their Determine their mother's information and their practices level about child's nutrition .

5-determine relationship between the degree of anemia among respondents children with independent variables like: some individual and family's characteristics, daily dietary pattern, mother's information level and mother's nutrition practices level .

Data were collected by personal interviews using questionnaires filled from 200 children's mothers attending three Mother and Child Health Care Units at Khafer El Dawar in Behera Governorate . Ratio percent , Sperman Correlation and Chi square were used for data analysis

The result of this study indicated that :

- $92 \%$ of children were suffering from anemia (35\% moderate \& $57 \%$ mild ) . 
- $04 \%$ of respondents children their weights were normal , $12 \%$ were underweight but $48 \%$ were overweight .

- $32 \%$ of children their lengths were normal , $41 \%$ from them were less than normal and $21 \%$ were more than normal length .

$-77 \%, 69 \%, 67 \%, 51 \%$ of the children respectively ate less than recommended daily allowance four food groups : meat, vegetables, milk and fruits .

- 53\%and $41 \%$ respectively of mothers their information level regarding child nutrition was poor and moderate, only $6 \%$ from them had good information level.

- $60 \%$ and $27 \%$ respectively of mothers their practices level about child nutrition was poor and moderate, only $3 \%$ from them had good practices level .
- There was significant negative relationships between the degree of infection anemia among respondents children with some independent variables like: weight of child, daily intake from follow food groups : cereals and its products, meat and its alternatives, milk and its products, fruits and vegetables, also There was negative significant relationships between anemic infection with weekly intake from eggs and meat .

- There was significant negative relationships between the degree of infection anemia among respondents children with their mother's education, mother's knowledge level, mother's practices level .

-There was significant positive relationship with children's drinking tea and member of their family . 